\title{
Audit of mortality in upper gastrointestinal bleeding
}

\author{
B.D. Katschinski ${ }^{1}$, R.F.A. Logan ${ }^{2}$, J. Davies $^{3}$ and M.J.S. Langman ${ }^{4}$ \\ ${ }^{1}$ Division of Gastroenterology, University Hospital Essen, FRG, ${ }^{2}$ Department of Community Medicine and \\ Epidemiology, University Hospital Nottingham, UK, ${ }^{3}$ Department of Therapeutics, University Hospital \\ Nottingham, UK and ${ }^{4}$ Department of Internal Medicine, Queen Elizabeth Hospital, Birmingham, UK.
}

\begin{abstract}
Summary: The outcome in 1017 patients with haematemesis and malaena referred to two major hospitals in Nottingham within a 2-year period has been prospectively evaluated. Ninety one $(9 \%)$ patients died during the time period under consideration and all but four were found to have been over 60 years of age. There were $13(14 \%)$ deaths following rebleeding, of whom $5(5 \%)$ could have been potentially avoided by alterations in management. Some improvement of mortality might result from intensive-care facilities with better management of transfusions and earlier detection of rebleeding allowing earlier endoscopy or surgery. The majority of patients $(81 \%)$, however, died from concomitant disease which was exacerbated by gastrointestinal haemorrhage or bleeding developed in patients with an already existing end-stage disease. These results show that a reduction of mortality in patients with gastrointestinal bleeding is hampered by the high number of poor-risk patients. The rise in the proportion of elderly patients with this disorder seems to continue.
\end{abstract}

Introduction

Mortality from upper gastrointestinal bleeding is reported to be about $10 \%$ in the United Kingdom and this rate has changed little if at all during the last time period. ${ }^{1}$ This unsatisfactory pattern may be in part due to changes in the population at risk because patients with upper gastrointestinal bleeding are known to be elderly thus being more prone for the development of other medical problems. ${ }^{2}$ Few published series have assessed the impact of these factors on mortality in patients with gastrointestinal bleeding in a defined population. ${ }^{3,4}$ The purpose of the present study was to determine what proportion of deaths would have been influenced by alterations in management.

\section{Methods}

We collected information about clinical and endoscopic characteristics, including the outcome, in 1017 patients admitted to Nottingham hospitals with haematemesis and/or melaena from 1 April 1984 to 31 March 1986. The Nottingham City and University Hospitals are the only acute admitting hospitals in this area serving a population of 789,000 . Information on

Correspondence: B.D. Katschinski, M.D., Medizinische Universitätsklinik, Abteilung für Gastroenterologie, Hufelandstraße 55, 4300 Essen 1, FRG.

Accepted: 17 July 1989. sociodemographic characteristics, severity of bleeding and endoscopic findings was recorded during the admission. The short-term outcome from admission to death or hospital discharge was noted for each patient. All hospital records of patients who died were reviewed and the causes of death analysed. For the purpose of this study deaths were classified according to the presence of a terminal disease such as cardiovascular, pulmonary, renal, hepatic and malignant disease. Deaths were regarded as being due to rebleeding when a drop in the haemoglobin level or fresh haematemesis or melaena occurred after admission accompanied by a breakdown of circulation.

The patients were admitted to general medical wards and were managed by physicians in consultation with a surgeon. Endoscopy was carried out within 24 hours after admission and, in the case of a severe episode of bleeding, at once. The operative rate was $11.9 \%$.

\section{Results}

\section{Source of haemorrhage}

The overall mortality rate from this series of gastrointestinal haemorrhage was $9 \%$ (Table I). Among the patients who died, peptic ulcers of the oesophagus, stomach and duodenum accounted for $53 \%$ of all deaths. Although the highest mortality rates were

The Fellowship of Postgraduate Medicine, 1989 
Table I Mortality of acute upper gastrointestinal bleeding by bleeding lesion and sex

\begin{tabular}{lccccc}
\hline Bleeding lesion & \multicolumn{2}{c}{ Admissions } & \multicolumn{2}{c}{ Deaths } & No. of \\
& Total no. & $(\%)$ & Total no. & $(\%)$ & females \\
\hline Gastric ulcer & 206 & $(20)$ & 24 & $(12)$ & 13 \\
Duodenal ulcer & 265 & $(26)$ & 25 & $(9)$ & 10 \\
Oesophageal ulcer & 30 & $(3)$ & 4 & $(13)$ & 1 \\
Erosions & 57 & $(6)$ & 3 & $(5)$ & 2 \\
Mallory-Weiss & 42 & $(4)$ & 1 & $(2)$ & - \\
Oesophageal varices & 35 & $(3)$ & 6 & $(17)$ & 4 \\
Gastric cancer & 13 & $(1)$ & 4 & $(31)$ & 4 \\
Other known lesions & 139 & $(14)$ & 8 & $(6)$ & 3 \\
No lesion found & 187 & $(18)$ & 13 & $(7)$ & 6 \\
Not examined & 43 & $(5)$ & 3 & $(7)$ & 1 \\
\hline
\end{tabular}

found in those with gastric carcinoma $(31 \%)$ and oesophageal varices $(17 \%)$ meaningful subgroup comparisons are difficult because of the small number of patients with these disorders. Patients without a positive final diagnosis had either no endoscopy performed ( 3 patients) or no lesion detected at endoscopy (13 patients). The first group consisted of patients with an end-stage disease, the latter group of patients who were admitted because of acute gastrointestinal symptoms with a past history of gastrointestinal bleeding.

In $80 \%$ of the patients the final diagnosis rested on the findings at endoscopy. In 5 patients post-mortem examination was performed to determine the site of bleeding because death followed rapid exsanguination in 3 patients and the remainder was made up of patients with advanced cancers.

\section{Causes of death}

Table II shows whether deaths followed surgery or medical treatment and whether the immediate cause of death was due to haemorrhage or concomitant disease. Among the nonoperated patients, $\mathbf{4 0}$ deaths were unrelated to haemorrhage and were due to other medical conditions the majority of which constituted malignant diseases and cardiopulmonary complications. Further analysis shows that deaths occurred among patients with major gastrointestinal bleeding in whom active management was impaired by the presence of concomitant disease $(18 \%)$. In these patients the causes of death were cardiac failure (4), bronchopneumonia (3), cor pulmonale (1), cerebrovascular accident (3), cancer (3), hepatic (1) and liver failure (1). Table III summarizes the causes of death in medically treated patients; 13 deaths $(14 \%)$ were due to recurrent bleeding developing rapidly before an operation could be performed. In these cases oesophageal varices were found in 5 patients, in the remaining 8, gastric and duodenal ulcers were identified in 5 and 3 patients, respectively. In 5 patients recurrent bleeding occurred after a time period of 24 hours, 8 deaths followed exsanguination within 12 hours after admission.

In 22 patients deaths resulted after surgery. Most of the postoperative deaths occurred in patients with longstanding chronic diseases which deteriorated in the event of bleeding, the medical conditions being

Table II Causes of death in 91 patients with upper gastrointestinal bleeding

\begin{tabular}{lcc}
\hline & No. of patients (\%) \\
\hline $\begin{array}{c}\text { Death after medical treatment } \\
\text { Bleeding mild, death due to } \\
\text { other medical conditions } \\
\text { Bleeding severe, active } \\
\text { management inhibited by }\end{array}$ & 40 & $(44)$ \\
$\quad$ concomitant disease & 16 & $(18)$ \\
$\begin{array}{l}\text { Death following massive } \\
\text { rebleeding }\end{array}$ & 13 & \\
$\begin{array}{l}\text { Death after surgery } \\
\text { Postoperative complications } \\
\text { Concomitant disease }\end{array}$ & 4 & \\
\hline
\end{tabular}

Table III Causes of death from concomitant disease in 56 medically treated patients

\begin{tabular}{lcc}
\hline & No. of patients & $(\%)$ \\
\hline Cardiac failure & 11 & $(20)$ \\
Cerebrovascular accident & 8 & $(14)$ \\
Bronchopneumonia & 11 & $(20)$ \\
Cor pulmonale & 4 & $(7)$ \\
Hepatic failure & 2 & $(4)$ \\
Renal failure & 2 & $(4)$ \\
Stomach cancer & 4 & $(7)$ \\
Other malignancies & 14 & $(25)$ \\
\hline
\end{tabular}


cardiac failure (7), bronchopneumonia (2), cor pulmonale (1), cerebrovascular accident (2), renal failure (1) and carcinoma of the stomach (2) and sigmoid colon (1). Surgical complications accounted for 4 postoperative deaths of whom 2 were due to pulmonary embolism and 2 were related to peritonitis.

The day-to-day decision whether the patient was a candidate for surgery was made by physicians and surgeons together. Of the 22 patients having a laparotomy performed, in 12 patients the surgical procedure was carried out within 72 hours of admission, in 4 patients surgery was performed within 4 to 6 days after admission and in 6 patients surgery was delayed for over 6 days. In the last group the source of bleeding had been identified at admission and surgery was carried out because of a late episode of rebleeding which did not stop spontaneously.

Table IV shows the causes of death in relation to the site of bleeding. Rebleeding as the fatal event occurred only in patients with gastric or duodenal ulcers or oesophageal varices. Postoperative complications were particularly frequent among patients bleeding from a gastric ulcer.

The management of patients with respect to blood transfusions was very similar whether the outcome of the bleeding episode was fatal or not. The percentage of patients who received no blood, 1-5 units and more than 5 units of blood was, for survivors of the bleeding episode, $21 \%, 52 \%$ and $27 \%$, respectively, and for patients with fatal outcome $23 \%, 55 \%$ and $22 \%$, respectively.

\section{Age distribution}

All but four patients who died because of gastrointestinal haemorrhage were more than 60 years of age, $71 \%$ being over the age of 70 and $41 \%$ over 80 . Table V
Table IV Causes of death by bleeding lesion

\begin{tabular}{|c|c|c|c|}
\hline & $\begin{array}{l}\text { Rebleeding } \\
(n=13)\end{array}$ & $\begin{array}{l}\text { Postoperative } \\
\quad(n=22)\end{array}$ & $\begin{array}{c}\text { Concomitant } \\
\text { disease } \\
(n=56)\end{array}$ \\
\hline Gastric ulcer: & $5(3)^{*}$ & 11 & 8 \\
\hline Duodenal ulcer: & $3(1)^{*}$ & 7 & 15 \\
\hline $\begin{array}{l}\text { Oesophageal } \\
\text { varices: }\end{array}$ & $5(4)^{*}$ & - & 1 \\
\hline $\begin{array}{l}\text { Other identified } \\
\text { lesion: }\end{array}$ & - & 4 & 16 \\
\hline No lesion found: & - & - & 16 \\
\hline
\end{tabular}

*Died within 12 hours after admission to hospital.

shows that there is a clear relationship between increasing age and fatality rates. In contrast, operation rates showed little variation with age except for the very elderly in whom the lowest operation rate was found $(7 \%)$. While age had no bearing on the occurrence of rebleeding the likelihood of serious medical conditions as major causes of death increased from the lowest to the highest age-band.

Of the 4 deaths occurring under the age of 60 , 2 patients died of exsanguination within 12 hours after admission, one patient developed peritonitis after surgery and one patient with a history of multiple sclerosis died of a stroke after polya gastrectomy was performed because of a bleeding gastric ulcer.

\section{Type of operation}

Table VI shows the fatality rates for the two most used types of operations in gastric and duodenal ulcer and in a miscellaneous group. Partial gastrectomy resulted in a fatality rate of about one quarter in all three diagnostic groups. Procedures like oversewing or

Table $\mathbf{V}$ Outcome in age groups by cause of death

\begin{tabular}{lcccccccc}
\hline $\begin{array}{l}\text { Age group } \\
\text { (years) }\end{array}$ & $\begin{array}{c}\text { No. of patients } \\
\text { admitted }\end{array}$ & \multicolumn{1}{c}{ (\%) } & No. of operations (\%) & No. of deaths (\%) & $\begin{array}{c}\text { Postoperative } \\
\text { complications }\end{array}$ & $\begin{array}{c}\text { Concomitant } \\
\text { disease }\end{array}$ \\
Rebleeding
\end{tabular}

Table VI Outcome following the main types of operation in three diagnostic groups

\begin{tabular}{|c|c|c|c|c|c|c|c|c|c|}
\hline \multirow{4}{*}{$\begin{array}{l}\text { Partial gastrectomy } \\
\text { Oversewing or vagotomy } \\
\text { and pyloroplasty }\end{array}$} & \multicolumn{3}{|c|}{ Duodenal ulcer } & \multicolumn{3}{|c|}{ Gastric ulcer } & \multicolumn{3}{|c|}{ Miscellaneous } \\
\hline & \multirow{2}{*}{$\begin{array}{r}\text { Total } \\
9\end{array}$} & \multicolumn{2}{|c|}{ No. of deaths (\%) } & \multirow{2}{*}{$\frac{\text { Total }}{25}$} & \multicolumn{2}{|c|}{ No. of deaths (\%) } & \multirow{2}{*}{$\frac{\text { Total }}{8}$} & \multicolumn{2}{|c|}{ No. of deaths (\%) } \\
\hline & & 2 & (22) & & 6 & (24) & & 2 & (25) \\
\hline & 59 & 5 & ( 8$)$ & 15 & 5 & (33) & 6 & 2 & (33) \\
\hline
\end{tabular}


vagotomy were in particular associated with a high number of complications $(33 \%)$ in gastric ulcer patients.

\section{Discussion}

The trend of unchanged mortality rates in upper gastrointestinal bleeding can be mainly accounted for by two factors which dominated the causes of death in the present study and may be accelerating. These factors are the high proportion of very elderly people presenting with gastrointestinal haemorrhage and the presence of serious medical conditions complicating management in those with minor and major haemorrhage.

Since we included all patients with substantial upper gastrointestinal haemorrhage being admitted to the two major Nottingham hospitals, incomplete assessment of high-risk patients such as geriatric patients seems to be unlikely. Case ascertainment in this study, however, did not consider patients who died at home because of an ulcer complication. This was an important mode of death in a recent study which found that sudden death at home occurred in $37 \%$ of all patients dying from peptic ulceration. ${ }^{5}$

Furthermore, in our study, the bulk of deaths was due to concomitant disease rather than to gastrointestinal bleeding which was likely to stop spontaneously. The distinction between self-limited haemorrhage and major rebleeding, however, was based on haemodynamic criteria and the clinical presentation in all but 5 patients in whom post-mortem examination was performed. Pathological criteria for the evidence of shock might have reduced the number of deaths classified as cardiac failure especially in those who died of rapid exsanguination.

Besides haemodynamic parameters the decision for treatment is based on the findings at endoscopy and the assessment of preoperative medical conditions. According to previous reports, postoperative deaths and deaths following rebleeding in patients without severe medical problems were classified as potentially inevitable. There were $35(38 \%)$ such deaths in this study, 18 occurring after surgery because of the exacerbation of a chronic disease, 4 following postoperative complications and 13 related to rapid exsanguination. In none of these does it seem to be likely that altered management would have prevented a substantial number of deaths.

The fatal outcome might have been influenced, however, in 7 patients, 2 of whom died of pulmonary embolism following surgery and 5 suffered from uncontrolled rebleeding later than 24 hours after admission to hospital. Postoperative heparin application and the management of patients with haemorrhage on an intensive care unit might have improved survival. A policy offering combined medical and surgical care for all patients with upper gastrointestinal haemorrhage has been shown to be associated with a fall in mortality in several study groups. ${ }^{6-10}$ Some improvement of mortality might result from intensive-care facilities with better management of transfusions, earlier detection of rebleeding allowing earlier endoscopy or surgery. A considerable number of patients in this series, however, did not die because of exsanguination, but suffered from advanced illness as the fatal events. The latter group of patients is unlikely to benefit from treatment on intensive care units. On the other hand a more aggressive surgical policy has failed to improve survival in the treatment of bleeding peptic ulcers in one of our own studies. ${ }^{11}$ One trial, however, indicated a reduction in mortality for patients over 60 treated by an aggressive surgical policy. ${ }^{12}$

According to the reported series the number of patients over 60 years of age suffering from upper gastrointestinal bleeding has increased steadily. ${ }^{2,13}$ In this study the proportion of patients over 60 years of age being admitted with gastrointestinal haemorrhage was $62 \%$, a greater increase in the number of elderly people than can be explained on the basis of population changes alone. The proportion of patients aged over 80 years of this series $(18 \%)$ has increased compared with the Nottingham series from 1975-79 which showed that $10 \%$ of the study population were over 80 years of age.

One might argue that the effect of a disproportionate increase of mortality in elderly people could have been brought about by improved diagnostic techniques attributed to the use of endoscopy. The trend of increasing bleeding episodes in the elderly has, however, continued after the introduction of endoscopy which suggests that endoscopy has not influenced this rise.

Environmental factors have to be considered to account for the changes in the population at risk. One factor which might have contributed to this shifting is the increased use of non-steroidal anti-inflammatory drugs in the elderly in whom ulcer complications have increased ${ }^{14}$ and peptic ulceration accounts for about half of all admissions with upper gastrointestinal bleeding. In a recent study we were able to show that people admitted to hospital with bleeding peptic ulcers over the age of 60 were about three times as likely to be takers of non-steroidal anti-inflammatory drugs than community controls. ${ }^{15}$ Reasons for the increased susceptibility of the elderly to these drugs are not yet understood. Furthermore, the impact of environmental exposures on different lesions of the gastrointestinal tract remains largely unknown

In summary, this analysis confirms prior reports from Scotland ${ }^{13}$ which showed that gastrointestinal bleeding occurs predominantly in patients with end- 
stage diseases who turn out to be poor candidates for a surgical approach which is still the standard procedure to stop haemorrhage. The management of patients who do not suffer from terminal diseases should be

\section{References}

1. Editorial. Bleeding ulcers: scope for improvement. Lancet 1984, i: 715-717.

2. Allan, R. \& Dykes, P. A study of the factors influencing mortality rates from gastrointestinal haemorrhage. $Q J$ Med 1976, 45: 533-550.

3. Johnston, S.J., Jones, P.F., Kyle, J. \& Nedham, C.D. Epidemiology and course of gastrointestinal haemorrhage in North-East Scotland. Br Med J 1973, 3: 655-660.

4. Madden, M.V. \& Griffith, G.H. Management of upper gastrointestinal bleeeding in a District General Hospital. $J$ Coll Physicians Lond 1986, 20: 212-215.

5. Blower, A.L. \& Armstrong, C.P. Sudden deaths at home from peptic ulceration - a hitherto unrecognised phenomenon. Gut 1986, 27: A1281.

6. Hunt, P.S., Hansky, J. \& Korman, M.G. Mortality in patients with haematemesis and melaena: a prospective study. Br Med J 1979, 1: $1238-1240$.

7. Devitt, J.E., Brown, F.N. \& Beattie, W.G. Fatal bleeding ulcer. Ann Surg 1966, 164: 840-844.

8. Hunt, P.S. \& Fancis, J.K. Reduction in mortality from upper gastrointestinal haemorrhage. Med J Aust 1983, 2: $552-555$. carried out on intensive care units. The increasing proportion of elderly people with this disorder seems to continue and environmental exposures have to be examined in this light.

9. Duggan, J.M. Haematemesis patients should be managed in special units. Med $J$ Aust 1986, 144: 247-249.

10. Dronfield, M.W. (Editorial). Special units for acute upper gastrointestinal bleeding. $\mathrm{Br} \mathrm{Med} J$ 1987, 294: $1308-1309$.

11. Dronfield, M.W., Atkinson, M. \& Langman, M.J.S. Effect of different operation policies on mortality from bleeding peptic ulcer. Lancet 1979, i: 1126-1128.

12. Morris, D.L., Hawker, P.C., Brearley, S., Simms, M., Dykes, P.W. \& Keighley, M.R.B. Optimal timing of operation for bleeding peptic ulcer: prospective randomised trial. Br Med J 1984, 288: 1277-1280.

13. Logan, R.F.A. \& Finlayson, N.D.C. Death in acute upper gastrointestinal bleeding. Can endoscopy reduce mortality. Lancet 1976, i: 1173-1175.

14. Walt, R., Katschinski, B., Logan, R., Ashley, J. \& Langman, $M$. Rising frequency of ulcer perforation in elderly people in the United Kingdom. Lancet 1988, i: 489-492.

15. Somerville, K.W., Faulkner, G. \& Langman, M.J.S. Non-steroidal anti-inflammatory drugs and bleeding peptic ulcer. Lancet 1986, i: 462-464. 